\title{
Plaque type variant of lichen planus
}

\section{Clinical images}

A 54years old male patient presented to the department of Oral medicine with the chief complaint of whitish discoloration of the tongue with burning sensation. On clinical examination, there was a whitish plaque like lesion present on the dorsum of the tongue involving left and right lateral borders extending bilaterally to the commissure of lip. The lesion was non tender and non- scrapable on palpation. Patient did not have any similar lesions on the skin. Clinical diagnosis of plaque type of lichen planus was given. Blood investigations were performed to rule out HIV and Hepatitis-B which were confirmed negative. To further confirm the diagnosis, incisional biopsy of the left lateral border of the tongue was performed. Histopathological reports confirmed the diagnosis of Oral lichen planus. The patient was started initially with systemic steroids and antioxidants capsules. Follow up of the patient showed no regression in the lesion but there was reduction in the burning sensation (Figure 1).

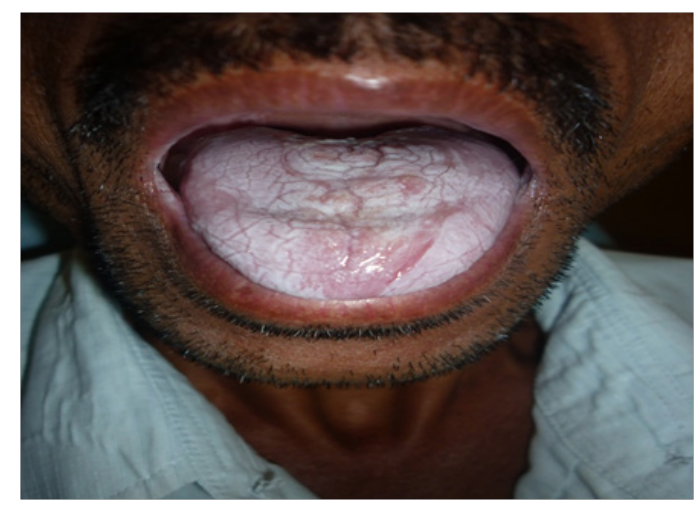

Figure I Patient showed no regression in the lesion.
Volume 5 Issue 2 - 2017

\author{
Devishree V Rai, Kruthika S Guttal, Krishna \\ N Burde \\ SDM College of Dental Sciences, India
}

Correspondence: Devishree V Rai, SDM College of Dental Sciences, \#305, Shantala Ashiyana Behind KPT,VYasnagar Kadri, India,Tel 9986773869, Email devishreerai@gmail.com

Received: October 26, 2017 | Published: December 14, 2017

\section{Acknowledgements}

None.

\section{Conflict of interest}

The author declares no conflict of interest. 